\title{
DISAIN KAPAL PENANGKAP IKAN 10 GT BERBAHAN FIBERGLASS UNTUK WILAYAH PERAIRAN KECAMATAN PANIMBANG KABUPATEN PANDEGLANG
}

\author{
Bambang Sudjasta (0325015802) dan \\ Yuhani Djaya (0301055302)
}

Fakultas Teknik, UPN "Veteran" Jakarta, karebet_m@yahoo.co.id

Fakultas Teknik, UPN "Veteran" Jakarta, yuhanidjaya@ymail.com

\begin{abstract}
The potential of Indonesian marine fisheries resources magnitude of \pm 6.6 million tons / year, but only some can be captured by Indonesian fishermen is \pm 4.7 million tons / year, partly stolen by fishermen from neighboring countries. This is due to the limited number and large size of fishing vessels operating. One of the areas that have the potential for capture fisheries is Panimbang Pandeglang District of Banten Province. Subdistrict of Panimbang the coastal region directly opposite the Sunda Strait. This region has a coastline and marine areas large enough.In order to improve the ability of the fishermen in the subdistrict Panimbang, it is necessary to build a fishing vessel that is suitable for this region. Where the design and construction of fishing vessel can be realized, then in turn the welfare of the fishermen in the region will increase. Fishing vessel designed the planned use of materials / raw materials fiberglass. This is because due to the high cost of steel plate material, problems also trouble getting wood materials. The fishing vessel design includes determining the size of the subject, the manufacturing line drawings, preparation of general plans, construction design, stability diagram, engine power and tonnage.
\end{abstract}

Keywords: design, fishing vessel, fiberglass

\section{PENDAHULUAN}

\section{Latar Belakang}

Potensi sumber daya perikanan laut Indonesia besarnya $\pm 6,6$ juta ton/tahun, tetapi baru sebagian yang dapat ditangkap oleh nelayan Indonesia yaitu \pm 4,7 juta ton/tahun, sebagian lagi dicuri oleh nelayan-nelayan negara tetangga. Hal ini disebabkan terbatasnya jumlah dan besar ukuran kapal ikan yang beroperasi.

Salah satu wilayah yang mempunyai potensi perikanan tangkap adalah Kecamatan Panimbang Kabupaten Pandeglang Provinsi Banten. Kecamatan Panimbang merupakan wilayah pesisir yang berhadapan langsung dengan Selat Sunda. Wilayah ini memiliki garis pantai dan wilayah laut yang cukup luas.

Dalam rangka meningkatkan kemampuan para nelayan di Kecamatan Panimbang, maka perlu didisain dan dibangun kapal perikanan yang sesuai untuk wilayah ini.

Di wilayah ini telah tersedia Pangkalan Pendaratan Ikan (PPI) yang mampu untuk berlabuh kapal perikanan sampai dengan maksimum ukuran kapal 10 Gross Tonnage (GT). Dari batasan-batasan fasilitas pendaratan yang tersedia, maka dapat dirancang Kapal Penangkap Ikan 10 GT. Tujuan

Tujuan penelitian adalah menentukan ukuran pokok kapal sebagai dasar pembuatan gambargambar disain kapal penangkap ikan.

Kapal yang dirancang direncanakan menggunakan material / bahan baku fiberglass. Hal ini mengingat disebabkan oleh mahalnya material pelat baja, juga permasalahan kesulitan mendapatkan material kayu. Disain kapal tersebut meliputi menentukan ukuran pokok, pembuatan gambar garis, penyusunan rencana umum, disain konstruksi, diagram stabilitas, daya mesin, dan tonage. Tinjauan Pustaka

PPI dan Kapal Perikanan

Pangkalan Pendaratan Ikan (PPI) merupakan pelabuhan Tipe $\mathrm{D}$, diperuntukkan bagi kapal perikanan yang beroperasi di perairan pedalaman dan perairan kepulauan. 
Kapal perikanan (Fisheries Vessel) adalah kapal, perahu, atau alat apung lain yang digunakan untuk melakukan penangkapan ikan, mendukung operasi penangkapan ikan, pembudidayaan ikan, pengangkutan ikan, pengolahan ikan, pelatihan perikanan dan penelitian/eksplorasi perikanan.

Tabel 1. Karakteristik Kelas Pelabuhan PPI

\begin{tabular}{|c|c|c|}
\hline $\begin{array}{l}\mathbf{N} \\
\mathbf{o}\end{array}$ & $\begin{array}{l}\text { Kriteria } \\
\text { Pelabuhan } \\
\text { Perikanan }\end{array}$ & PPI \\
\hline 1 & $\begin{array}{l}\text { Daerah operasional } \\
\text { kapal ikan yang } \\
\text { dilayani }\end{array}$ & $\begin{array}{l}\text { Perairan } \\
\text { pedalaman dan } \\
\text { perairan } \\
\text { kepulauan }\end{array}$ \\
\hline 2 & $\begin{array}{l}\text { Fasilitas } \\
\text { tambat/labuh kapal }\end{array}$ & $3-10 \mathrm{GT}$ \\
\hline 3 & $\begin{array}{l}\text { Panjang dermaga } \\
\text { dan Kedalaman } \\
\text { kolam }\end{array}$ & $\begin{array}{l}50-100 \mathrm{~m} \\
\mathrm{dan}>2 \mathrm{~m}\end{array}$ \\
\hline 4 & $\begin{array}{l}\text { Kapasitas } \\
\text { menampung kapal }\end{array}$ & $\begin{array}{l}>60 \text { GT (ekivalen } \\
\text { dgn } 20 \text { buah } \\
\text { kapal berukuran } 3 \\
\text { GT) }\end{array}$ \\
\hline 5 & $\begin{array}{l}\text { Volume ikan yang } \\
\text { didaratkan }\end{array}$ & - \\
\hline 6 & Ekspor ikan & Tidak \\
\hline 7 & Luas lahan & $2-5 \mathrm{Ha}$ \\
\hline 8 & $\begin{array}{l}\text { Fasilitas } \\
\text { pembinaan mutu } \\
\text { hasil perikanan }\end{array}$ & Tidak \\
\hline 9 & $\begin{array}{l}\text { Tata ruang (zonasi) } \\
\text { pengolahan/penge } \\
\text { mbangan industri } \\
\text { perikanan }\end{array}$ & Tidak \\
\hline
\end{tabular}

Kapal penangkap ikan (Fishing Vessel) adalah kapal perikanan yang secara khusus dipergunakan untuk menangkap ikan termasuk menam pung, menyimpan, mendinginkan atau mengawetkan.

Terkait dengan Peraturan Menteri Kelautan dan Perikanan Nomor 2 Tahun 2015 tentang larangan penggunaan alat penangkap ikan (API) pukat hela (trawl) dan pukat tarik (seine nets) di wilayah Pengelolaan Perikanan Negara Republik Indonesia, maka alat penangkap ikan pada kapal ini direncanakan menggunakan pancing (hoke and lines) atau menggunakan jaring insang (gillnets).

\section{Ukuran Utama dan Rencana Umum}

Ukuran utama (principal particular atau main dimension) sebuah kapal yang dimaksud adalah meliputi panjang (L), lebar (B), tinggi (H atau D) dan sarat (T atau d), koefisien bentuk, berat kapal kosong (Lwt) dan daya angkut / bobot mati (Dwt). Koefisien bentuk sebuah kapal terdiri dari koefisien blok $(\mathrm{Cb})$, koefisien tengah kapal $(\mathrm{Cm})$, koefisien garis air $(\mathrm{Cw})$, dan koefisien prismatik (Cp).

Syarat utama yang perlu diperhatikan dalam menentukan ukuran utama adalah:

1) Displsemen $(\Delta)$ adalah berat kapal keseluruhan atau berat air yang dipindahkan oleh badan kapal yang terapung/tercelup.

2) Gross Tonnage (GT) adalah ukuran volume seluruh ruang pada kapal.

3) Kecepatan dinas (Vs) adalah kecepatan normal yang diinginkan pada saat kapal berlayar.

Metode perhitungan dalam menentukan ukuran utama kapal pada umumnya digunakan metode perbandingan (comparison method) dan metode iterasi (trial and error). Metode perbandingan digunakan karena relatif lebih mudah, dan metode iterasi diperlukan untuk ketelitian.

Berdasarkan hasil perhitungan ukuranukuran pokok kapal maka dapat dibuat perhitungan dan gambar rencana garis (lines plan). Pada rencana garis kapal (lines plan) menggambarkan tiga unsur gambar yang terdiri dari body plan, sheer plan, dan half breath plan.

Hidrostatika dan bonjean menunjukkan karakteristik yang menyangkut kemampuan apung serta parameter dalam berbagai kondisi pada kapal, kurva-kurva yang digambarkan antara lain: displacement, luasan garis air, titik tekan ke atas, koefisien-koefisien, dan metacenter.

Rencana umum yang dimaksud adalah rencana pembagian kompartemen, penempatan peralatan dan perlengkapan kapal antara lain:

- Sekat-sekat kedap air;

- Ruang ABK (crew);

- Peralatan dan perlengkapan deck;

- Peralatan akomodasi;

- Mesin kemudi dan peralatan nautis;

- Perlengkapan keselamatan pelayaran;

- Peralatan pemadam kebakaran.

\section{Konstruksi dan Daya Mesin}

Bahan/material fiberglass tersebut akan dibentuk menjadi pelat, frame, web, dan stiffener, dengan kategori marine use. Penentuan tebal lapisan pelat dan modulus-modulus elemen konstruksi mengacu pada peraturan klasifikasi dan konstruksi kapal laut yang dikeluarkan oleh Biro Klasifikasi dan/atau peraturan Non Convention Vessel Standard (NCVS). Bagian-bagian kapal yang dihitung tebal lapisan pelat dan modulus-modulus adalah: pelat kulit, geladak, konstruksi alas, gading-gading, sekat, linggi haluan dan buritan dan lain-lain. Daya mesin efektif kapal (Pe) 
$\mathrm{Pe}=\mathrm{R} \times \mathrm{Vs}$

$\mathrm{R}$ adalah hambatan kapal yang terdiri dari: hambatan gesek, gelombang, bentuk, udara, dan hambatan lain-lain.

$\mathrm{R}=\mathrm{Cr} \times(1 / 2 \times \mathrm{p} \times \mathrm{V} 2 \times \mathrm{S})$

$\mathrm{Vs}=$ kecepatan kapal

\section{Tonnage dan Stabilitas}

Penentuan Gross Tonage (GT) kapal menurut cara pengukuran dalam negeri, dihitung sesuai dengan ketentuan dalam Keputusan Dirjen PERLA No. PY.67/1/16-02, dengan rumus sebagai berikut:

\section{GT $=0,25 \times$ V}

Keterangan:

$\mathrm{V}=$ adalah jumlah isi dari ruangan di bawah geladak atas ditambah dengan ruangan-ruangan di atas geladak atas yang tertutup sempurna yang berukuran tidak kurang dari 1 meter kubik.

Stabilitas kapal adalah kemampuan ke posisi tegak setelah mendapat gaya dari luar yang menyebabkan kemiringan kapal. Untuk menjamin keselamatan dalam pelayarannya maka kapal harus mempunyai stabilitas yang baik. Stabilitas kapal sangat dipengaruhi oleh kedudukan 3 (tiga) buah titik, yaitu:

1) Titik pusat berat kapal $(G)$

2) Titik pusat gaya tekan ke atas (B) dari air yang dipindahkan oleh badan kapal

3) Titik metacenter (M)

Kapal yang stabilitasnya baik apabila letak titik $\mathrm{G}$ berada di bawah titik $\mathrm{M}$ dan berada di atas titik B.

\section{METODE PENELITIAN}

\section{Alur Metode Penelitian}

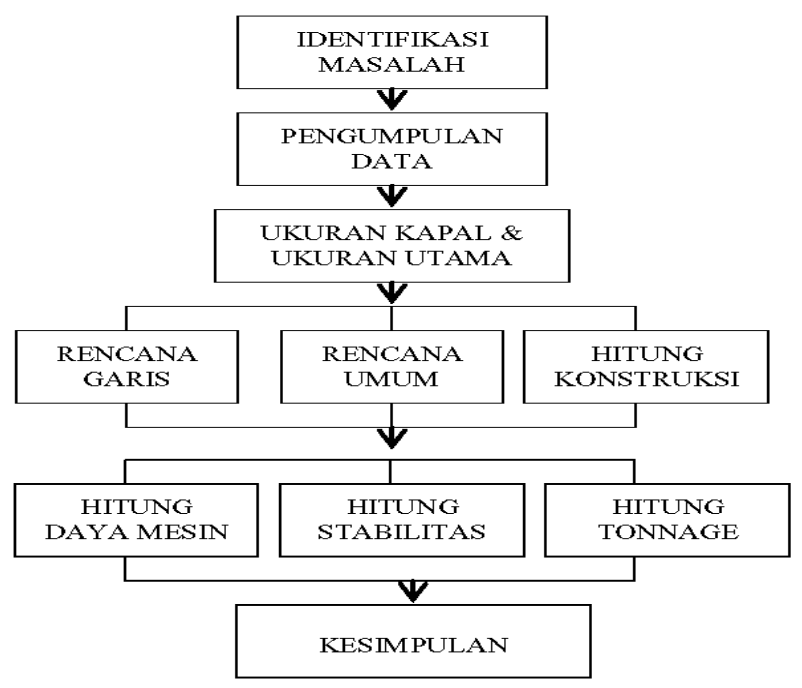

Gambar 1. Bagan Alur Metode Penelitian
Tabel 2. Uraian Metode Penelitian

\begin{tabular}{|c|c|c|}
\hline No & Kegiatan & Hasil \\
\hline 1 & $\begin{array}{l}\text { Identifikasi } \\
\text { masalah }\end{array}$ & $\begin{array}{l}\text { Masalah kriteria pelabuhan; } \\
\text { Masalah ukuran GT kapal }\end{array}$ \\
\hline 2 & $\begin{array}{l}\text { Pengumpulan } \\
\text { data }\end{array}$ & $\begin{array}{l}\text { Data pelabuhan: kedalaman } \\
\text { kolam, panjang dermaga, } \\
\text { data GT kapal yang beroperasi }\end{array}$ \\
\hline 3 & \begin{tabular}{l|} 
Penentuan \\
ukuran GT kapal \\
dan ukuran utama \\
kapal
\end{tabular} & $\begin{array}{l}\text { Ukuran GT kapal yang } \\
\text { sesuai; displacement, } \\
\text { panjang, lebar, tinggi, sarat, } \\
\text { koefisien }\end{array}$ \\
\hline 4 & \begin{tabular}{l|} 
Rencana garis \\
\end{tabular} & $\begin{array}{l}\text { Rencana garis bangunan } \\
\text { kapal, hidrostatika, bonjean }\end{array}$ \\
\hline 5 & Rencana umum & $\begin{array}{l}\text { Tata letak peralatan dan } \\
\text { ruang muat serta spesifikasi }\end{array}$ \\
\hline 6 & $\begin{array}{l}\text { Menghitung daya } \\
\text { mesin }\end{array}$ & $\begin{array}{l}\text { Daya mesin yang efektif dan } \\
\text { efisien }\end{array}$ \\
\hline 7 & \begin{tabular}{l|} 
Menghitung \\
konstruksi
\end{tabular} & $\begin{array}{l}\text { Modulus sesuai yang } \\
\text { dipersyaratkan BKI atau } \\
\text { NCVS }\end{array}$ \\
\hline 8 & $\begin{array}{l}\text { Menghitung } \\
\text { stabilitas }\end{array}$ & Stabilitas statis dan dinamis \\
\hline 9 & $\begin{array}{l}\text { Menghitung } \\
\text { tonage }\end{array}$ & $\begin{array}{l}\text { Tonage sesuai dengan yang } \\
\text { diinginkan }\end{array}$ \\
\hline 10 & Kesimpulan & $\begin{array}{l}\text { Kapal penangkap ikan yang } \\
\text { laik laut, laik tangkap,laik simpan }\end{array}$ \\
\hline
\end{tabular}

\section{HASIL DAN PEMBAHASAN}

\section{Ukuran Kapal dan Ukuran Utama Kapal}

Pengelolaan dan pembinaan PPI Panimbang berada di bawah Dinas Kelautan dan Perikanan Kabupaten Pandeglang. Kedalaman kolam waktu pasang $\pm 2,5$ meter, waktu surut $\pm 1,5$ meter. Kunjungan kapal rata-rata 25 kapal penangkap ikan per hari dengan ukuran 10 GT ke bawah.

Berdasarkan data-data yang diperoleh terkait PPI Panimbang, maka ditetapkan bahwa kapal penangkap ikan yang dirancang berukuran $10 \mathrm{GT}$.

Dari hasil perhitungan di atas maka ukuran utama kapal dan koefisien bentuknya untuk kapal penangkap ikan 10 GT yang dirancang ditetapkan sebagai berikut:

- Panjang seluruh kapal (Loa) : :14,00 m

- Panjang antara garis tegak (Lpp) :13,00 m

- Panjang garis air (Lwl) $\quad: 13,50 \mathrm{~m}$

- Lebar kapal (B) : $\quad: 10 \mathrm{~m}$

- Tinggi geladak $(\mathrm{H}) \quad: 1,80 \mathrm{~m}$

- Tinggi sarat air (T) : $0,90 \mathrm{~m}$

- Coefisien block $(\mathrm{Cb}) \quad: 0,55$

- Koefisien tengah kapal $(\mathrm{Cm}) \quad: 0,76$

- Koefisien garis air $(\mathrm{Cw}) \quad: 0,74$

- Koefisien prismatik $(\mathrm{Cp}) \quad: 0,72$

\section{b. Rencana Garis}

Gambar rencana garis kapal (lines plan) menggambarkan tiga unsur gambar yang terdiri dari body plan yang menggambarkan besarnya 
luasan tiap-tiap section kapal, sheer plan yang menggambarkan potongan-potongan tegak memanjang kapal, serta half breath plan yang menggambarkan luasan-luasan garis air kapal. Pembuatan gambar rencana garis digunakan software Maxsurf.

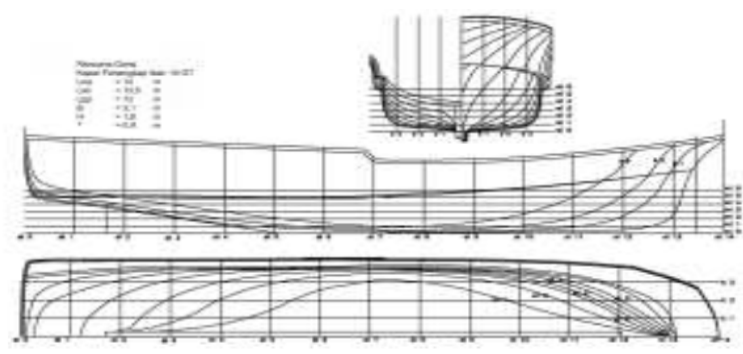

Gambar 2. Rencana Garis (Lines Plan)

\section{Rencana Umum}

Rencana umum menjelaskan rancang bangun kapal penangkap ikan kapasitas 10 GT, dapat beroperasi di pesisir perairan 10 mil dari pantai Panimbang selama 10 jam. Jenis kapal nelayan ini direncanakan dibangun dari bahan Fibreglass Reinforced Plastic (FRP).

Lambung kapal dibangun dengan program rancang bangun yang baik sehingga menghasilkan kapal yang optimal, effisien, layak laut, laik tangkap, dan laik simpan.

Untuk menunjang hull yang prima, dipasang 1 (satu) unit mesin diesel 54 daya kuda (HP) untuk mendorong kapal pada kecepatan jelajah 8 knot (continous).

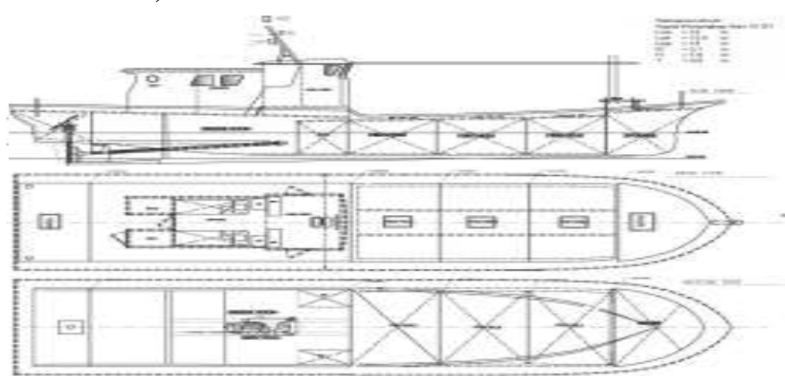

Gambar 3. Rencana Umum

\section{Daya Mesin}

Untuk menentukan besarnya daya mesinyang dibutuhkan guna menggerakkan kapal dengan kecepatan tertentu dibutuhkan perhitungan tahanan lambung kapal berdasarkan data faktor bentuk dan nilai hidrostatis dari bentuk lambung kapal sesuai dengan rencana garis (Lines Plan) kapal. Perhitungan hambatan menggunakan software "Hullspeed" dengan input: Analysis speed: pada kecepatan 0 s/d 10 knot.

Dari hasil analisis untuk perhitungan power dengan kecepatan 9 knot didapatkan power sebesar 53,703Hp atau $54 \mathrm{Hp}$.

\section{Kontruksi}

Pada pembuatan kapal fiberglass ada beberapa hal yang perlu diperhatikan, diantaranya komposisi bahan dan lapisan fiberglass yang digunakan baik itu untuk Lunas (keel), Bottom, Lambung,Gading-gading/kerangka dan bagian lain dari kapal fiber yang akan dibuat. Selain komposisi bahan ketebalan bahan yang digunakan juga merupakan hal yang perlu diperhatikan

Semua material beserta perlengkapannya yang dipergunakan untuk pembuatan kapal perikanan ini adalah baru, dengan material yang mempunyai kualitas uji bahan yang baik dan khusus digunakan di laut. Meterial tersebut antara lain gel coat (termasuk pigmen warna sesuai owner), Mat 300, Mat 450, SM 1250.

Material yang dipakai untuk struktur lambung menggunakan bahan fibreglass dengan ketebalan minimal sebagai berikut :

Tabel 3. Ketebalan Struktur

\begin{tabular}{|c|c|c|}
\hline No & Struktur & Tebal \\
\hline 1 & Lunas (keel) & $20 \mathrm{~mm}$ \\
\hline 2 & Dasar (bottom) & $14 \mathrm{~mm}$ \\
\hline 3 & Lambung (hull) & $8 \mathrm{~mm}$ \\
\hline 4 & $\begin{array}{l}\text { Gading-gading/kerangka } \\
\text { (frame) Meliputi gading pada bot } \\
\text { lambung dan di bawah main } \\
\text { deck. Menggunakan profil U } \\
\text { ukuran } 50 \times 50 \mathrm{~mm} \text {. }\end{array}$ & $\begin{array}{l}7 \mathrm{~mm} \\
\mathrm{om} \text {, }\end{array}$ \\
\hline 5 & $\begin{array}{l}\text { Lantai deck: } \\
\text { Lantai ruang akomodasi } \\
\text { Deck utama } \\
\text { Khusus untuk lantai / geladak } \\
\text { agar dipasang lapisan anti slip }\end{array}$ & $\begin{array}{l}6 \mathrm{~mm} \\
8 \mathrm{~mm}\end{array}$ \\
\hline 6 & Bangunan atas & $6 \mathrm{~mm}$ \\
\hline
\end{tabular}

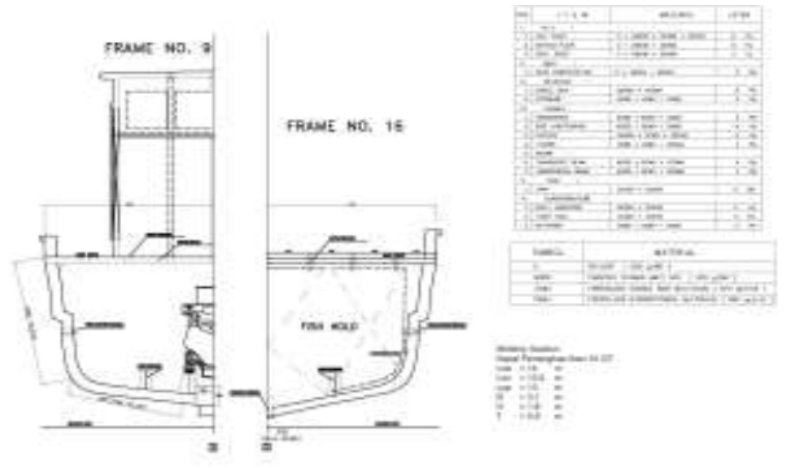

Gambar 4. Midship Section 


\section{Stabilitas}

\section{Kondisi Muatan Kapal Penuh (Displacement)}

Hasil analisis stabilitas untuk kondisi kapal muatan penuh berdasarkan kriteria International Maritime Organization (IMO) menunjukkan bahwa ketenggelaman kapal, baru akan terjadi apabila kemiringan kapal melebihi 750, sesuai Gambar 5.

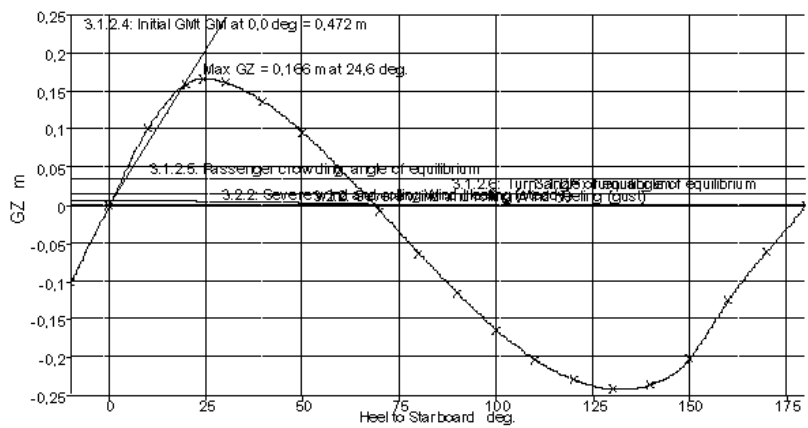

Gambar 5. Kurva Stabilitas

Periode oleng kapal 8,64 (s) dapat dikatakan kapal mempunyai stabilitas yang cukup nyaman pada gerak kapal dan untuk awak kapal.

\section{Gross Tonnage (GT)}

Penentuan GT kapal menurut cara pengukuran dalam negeri, dihitung sesuai dengan ketentuan dalam Keputusan Dirjen PERLA No. PY.67/1/1602, hasilnya adalah 10,36.

\section{KESIMPULAN}

PPI (pelabuhan tipe D) diperuntukkan kapal ikan yang beroperasi di perairan kepulauan dan pedalaman. Fasilitas tambat hanya untuk kapal ikan maksimum 10 GT. Berdasarkan data hasil survey di PPI Panimbang, maka ditetapkan bahwa kapal penangkap ikan yang dirancang berkapasitas $10 \mathrm{GT}$.

Ukuran pokok kapal kapal penangkap ikan 10 GT yang dirancang ditetapkan sebagai berikut:

- Panjang seluruh kapal (Loa) $\quad: 14,00 \mathrm{~m}$

- Panjang antara garis tegak (Lpp) : 13,00 m

- Panjang garis air (Lwl) : 13,50 m

- Lebar kapal (B) : :3,10 m

- Tinggi geladak $(\mathrm{H}) \quad: 1,80 \mathrm{~m}$

- Tinggi sarat air (T) $\quad: 0,90 \mathrm{~m}$

Mesin penggerak:

- Mesin penggerak $\quad: 54 \mathrm{HP}$

- Kecepatan :8 knot

- Lama operasi $\quad: 10 \mathrm{jam}$

Alat tangkap dan penyimpanan:

- Perlengkapan alat tangkap jaring sodong (pukat hela)

- Palka Ikan (Ikan + Es): 4 ton
Stabilitas kapal:

Ketenggelaman kapal, baru akan terjadi apabila kemiringan kapal melebihi 750 .

Periode oleng kapal 8,64 (s) dapat dikatakan kapal mempunyai stabilitas yang cukup nyaman pada gerak kapal dan untuk awak kapal.

Keadaan kapal yang memenuhi persyaratan material, konstruksi, bangunan, permesinan dan perlistrikan, stabilitas, tata susunan serta perlengkapan termasuk perlengkapan alat penolong dan radio, elektronik kapal, akan menjamin keselamatan kapal dalam pelayaran.

Ketebalan, komposisi bahan, dan lapisan fiberglass yang akan digunakan harus sesuai ketentuan konstruksi di laut. Disain kapal penangkap ikan 10 GT ini menjamin kapal yang laik laut, laik tangkap, dan laik simpan.

\section{DAFTAR PUSTAKA}

Departemen Pendidikan dan Kebudayaan Republik Indonesia, Direktorat Pendidikan Menengah Kejuruan, (1982), Teori Bangunan Kapal 2, Jakarta.

Ditjen Perikanan Tangkap, KKPRI, (2014), Buku Laporan Tahunan Statistik Perikanan Tangkap Tahun 2013.

E.V. Lewis, (1988), Principles of Naval Architecture, Volume II, Society of Naval Architects and Marine Engineers.

Jusuf Sutomo, (1992), Tahanan dan Propulsi Kapal, Airlangga University Press, Surabaya.

Tamaela Marthin, (1996), Merancang Kapal, Unsada, Jakarta. 